\title{
EKSPLORASI ETNOMATEMATIKA ACARA ADAT THELAS KETA PADA MASYARAKAT NOEMUTI
}

\author{
Dominikus Kou ${ }^{1}$, Yohanis Ndapa Deda ${ }^{2 *}$ \\ ${ }^{1}$ Mahasiswa Pendidikan Matematika Universitas Timor, ${ }^{2}$ Universitas Timor \\ *yndapadeda@unimor.ac.id
}

Dikirim: 23 Februari 2020 Diterima: 11 April 2020 Dipublikasikan: 31 Juli 2020

\begin{abstract}
ABSTRAK
Pada hakekatnya matematika merupakan ilmu pengetahuan yang digunakan untuk menyelesaikan masalah sehari - hari, sedangkan budaya merupakan pola hidup yang terdapat dalam masyarakat yang diwariskan secara turun - temurun. Keterkaitan antara matematika dan budaya dikenal dengan istilah etnomatematika. Etnomatematika merupakan matematika tumbuh dan berkembang dalam budaya. Dengan menerapkan etnomatematika sebagai suatu pendekatan pembelajaran akan sangat memungkinkan siswa untuk lebih paham dengan materi yang diajarkan. Penelitian ini bertujuan untuk menganalisis etnomatematika yang terkandung dalam acara adat thelas keta pada masyarakat Noemuti. Teknik pengumpulan data dalam penelitian ini dilakukan dengan observasi, wawancara dan dokumentasi. Teknik analisis data dilakukan dengan reduksi data, penyajian data, dan penarikan kesimpulan. Hasil penelitian menunjukkan bahwa dalam acara adat thelas keta terdapat beberapa konsep matematika antara lain : konsep garis, konsep bangun datar lingkaran, dan konsep bangun datar belah ketupat, konsep bangun datar persegi panjang. Dengan demikian peneliti merekomendasikan agar guru mengembangkan pembelajaran berbasis budaya dalam hal ini berbasis acara adat thelas keta pada materi konsep garis, konsep bangun datar lingkaran, dan konsep bangun datar belah ketupat dan konsep bangun datar persegi panjang. Tujuannya adalah untuk menjembatani matematika dengan budaya lokal sebagai salah satu sumber pembelajaran yang konkret sehingga siswa terlibat aktif dalam kegiatan belajar mengajar.
\end{abstract}

Kata kunci: acara adat thelas keta, etnomatematika.

\begin{abstract}
The essence of mathematics is a tool to solve daily problems, while culture is a pattern life that was found in the community that verbally inherit from generation to generation. The links between math and culture is known to the term etnomatematika .Etnomatematika is mathematics grow and grow in culture. By applying ethnomathematics as an approach of learning would be very enables the student to better informed with the materials given. This study aims to to analyze ethnomathematics contained in a customary ceremony noemuti thelas keta to the community. The technique of data collection during the research was conducted by observation, interviews and documentation. Technique data analysis data was undertaken by reduction, presentation of data, and the withdrawal of conclusion. The research results show that in a customary ceremony thelas keta there are several a mathematical conception of among other: the concept of a line, circle, rhombus, and rectangle. The purpose is for connecting local culture as one of concrete source of learning so that empowering students to engage in learning activity.
\end{abstract}

Keywords: thelas keta, ethnomathematics.

\section{Pendahuluan}

Matematika dan budaya merupakan dua hal yang mempunyai kaitan erat dalam kehidupan sehari - hari. Karena matematika merupakan salah satu ilmu pengetahuan yang digunakan manusia dalam menyelesaikan masalah sehari - hari sedangkan budaya merupakan suatu pola hidup menyeluruh yang berlaku di masyarakat dan diwariskan dari generasi ke generasi. Matematika terwujud karena adanya kegiatan manusia (Soedjadi dalam Angriani 2013 : 57). Sedangkan wujud dari budaya itu adalah segala bentuk rangkaian tindakan dan aktivitas manusia yang berpola. Keterkaitan antara matematika dan budaya dikenal dengan etnomatematika.

Menurut (Astri Wahyuni, Ayu Anji Wedaring Tias \& Budiman Sani 2013 : 2) etnomatematika adalah bentuk matematika yang dipengaruhi atau didasarkan budaya. Ini berarti bahwa konsep matematika dapat digali dan ditemukan dalam budaya sehingga dapat dimanfaatkan sebagai sumber belajar konkret yang ada disekitar siswa. Etnomatematika juga bisa dipandang sebagai jembatan antara matematika dan budaya. Dengan menerapkannya etnomatematika sebagai suatu pendekatan pembelajaran akan sangat memungkinkan siswa untuk lebih paham dengan materi yang diajarkan karena langsung terkait dengan budaya mereka yang merupakan aktivitas sehari - hari. 
Lebih lanjut dikatakan oleh D' Ambrosio (dalam Turmudi, 2017 : 3) bahwa kurikulum matematika sekolah harusnya kompatibel (selaras) dengan bentuk - bentuk budaya, tetapi hal ini tidak berarti bahwa etnomatematika menggantikan kurikulum matematika. Akan tetapi kurikulum matematika sekolah harus menyertakan etnomatematika sehingga dapat memfasilitasi siswa untuk mendapatkan pengetahuan, pemahaman, menyelaraskan pengetahuan dan pemahamannya dengan praktik - praktik budaya yang memang sudah sangat dikenal oleh mereka sebelumnya (Gerdes dalam Turmudi 2017 : 3). Dengan menyertakan etnomatematika dalam kurikulum sekolah akan memberikan nuansa baru dalam pendidikan matematika di sekolah dengan pertimbangan bahwa Indonesia terdiri atas berbagai macam suku budaya dan setiap suku memiliki cara tersendiri dalam menyelesaikan masalah yang dihadapi (Sirate 2012: 41).

Akan tetapi fakta menunjukkan bahwa pembelajaran matematika di sekolah sering disajikan terlalu formal, terkesan kaku dan kurang menyenangkan serta masih jauh berbeda dengan yang ditemukan dalam kehidupan sehari - hari. Hal ini disebabkan karena metode yang digunakan guru dalam pembelajaran di kelas adalah metode ceramah (konvensional) yang selalu berpusat pada buku pelajaran. Dengan metode konvensional juga siswa kurang terlibat aktif dalam proses belajar mengajar sehingga siswa kurang diberi kesempatan utuk berdiskusi dalam menjawab suatu permasalahan. Hal ini menyebabkan kreativitas siswa kurang berkembang karena tidak terbiasa untuk bekerja sama dalam menyelesaikan suatu permasalahan. Dengan demikian siswa merasa bosan dan malas dalam mengikuti pelajaran matematika. Akibatnya timbul sebuah konsep dalam ruang lingkup siswa dengan beranggapan bahwa matematika merupakan sebuah ilmu yang rumit, membosankan, banyak rumus dan tidak berguna.

Oleh karena itu dalam pembelajaran matematika perlu diawali dengan pengetahuan informal yang telah dimiliki siswa dalam mempelajari matematika di sekolah. Salah satu alternatif dan menjadi fokus dalam penelitian ini adalah dengan mengeksplorasi konsep - konsep matematika yang terkandung dalam acara adat thelas keta pada masyarakat Noemuti secara spesifik seperti perlengkapan yang dibawa, dan juga pakaian adat yang dipakai pada saat mengikuti acara adat thelas keta. Secara umum proses adat perkawinan thelas keta, pantangan, dan alat dan bahan yang digunakan telah dibahas oleh Deda dan Disnawati (2019). Tetapi mereka belum mengungkap konsep-konsep matematika yang terkandung dalam proses perkawinan adat Thelas Keta. Beberapa eksplorasi aktivitas matematika yang ada dalam budaya masyarakat Kabupaten Timor Tengah Utara yaitu Amsikan dan Nahak (2017) mengeksplorasi beberapa konsep geometri yang terdapat dalam rumah adat ume kbubu, Deda dan Disnawati (2017) mengeksplorasi konsep-konsep geometri yang terdapat dalam motif kain tenun Suku Dawan, Son (2017) telah mengungkap konsep matematika pada permainan kelereng masyarakat Suku Dawan , Funan dan Mamoh (2019) juga telah melihat konsep geometri pada Uem Le'u Insana. Eksplorasi lebih lanjut tentang konsep geometri yang terkandung dalam motif kain tenun yang ada di masyarakat kefamenanu juga telah dilakukan oleh Deda dan Amsikan (2019). Hasil eksplorasi konsep matematika pada acara adat perkawainan thelas keta dapat dijadikan sebagai konteks dalam pengembangan bahan ajar matematika yang berbasis budaya lokal di Kabupaten TTU untuk memudahkan pembelajaran di kelas dan diharapkan dapat meningkatkan motivasi belajar matematika siswa sekolah dasar dan menengah.

\section{Metode Penelitian}

Penelitian ini termasuk dalam penelitian eksploratif dengan pendekatan etnografi. Pendekatan etnografi memfokuskan usaha untuk menemukan bagaimana masyarakat mengorganisasikan budaya mereka dalam pikiran mereka dan kemudian menggunakannya dalam kehidupan, budaya tersebut ada dalam pikiran manusia (Spradley, 2006). Penelitian ini dilakukan di sungai Noemuti saat berlangsungnya upacara thelas keta pada tanggal 22 April 2019. Subyek dalam penelitian ini ada dua orang narasumber. Narasumber pertama Bapak Yohanes Laot selaku kepala adat Desa Seo Kecamatan Noemuti yang berusia 70 tahun dan narasumber kedua Bapak Marselinus Manue Solo selaku pembicara atau penutur adat dalam acara adat thelas keta yang berusia 72 tahun. Obyek dalam penelitian ini adalah acara adat thelas keta pada masyarakat Noemuti. Teknik pengumpulan data dilakukan dengan observasi, wawancara dan dokumentasi. Teknik analisis data dilakukan dengan reduksi data, penyajian data, dan penarikan kesimpulan. 


\section{Hasil Penelitian dan Pembahasan}

\section{a. $\quad$ Sekilas Tentang Acara Adat Thelas Keta}

Secara etimologi istilah thelas keta berasal dari bahasa Dawan yang terdiri dari dua kata yaitu kata thelas yang berarti menarik atau membatasi dan keta yang berarti lidi dari pohon lontar. Jadi thelas keta artinya menarik lidi.

Upacara thelas keta adalah sebuah upacara rekonsiliasi antar wilayah dalam daerah Dawan. Upacara ini bertujuan untuk mengesampingkan atau mengabaikan halangan - halangan yang terjadi akibat peperangan. Peperangan itu terjadi karena kasus pencurian dan juga kasus perampasan wilayah. Akibat peperangan tersebut maka terjadi banyak korban dari kedua belah pihak. Pengalaman pengalaman seperti ini mendorong mereka untuk membangun halangan secara budaya bahwa mereka tidak akan saling menikah satu sama lain.

Upacara thelas keta yang dimaksudkan untuk mengabaikan atau menghilangkan halangan halangan yang telah terjadi karena berbagai pengalaman peperangan dan permusuhan tersebut dikenal dengan istilah taaib beb'e katan ma asu nisin. Secara harafiah kata taaib artinya mengelakan atau mengesampingkan sesuatu dan beb'e katan artinya duri dari pelepah lontar atau gewang, yang bisa melukai seseorang jika kurang berhati - hati. Sedangkan asu nisin artinya gigi anjing. Kedua ungkapan itu merupakan simbol bahaya yang bisa ditimbulkan dari pernikahan antara dua orang yang berasal dari dua wilayah yang berbeda dalam wilayah Dawan tanpa sebuah upacara thelas keta. Upacara thelas keta ini mempunyai makna perdamaian kembali atas kelompok etnis yang pernah bermusuhan satu sama lain karena berbagai alasan sehingga kedua mempelai yang akan menikah tidak mendapatkan halangan dalam diri mereka maupun pada keturunan mereka kelak.

Upacara thelas keta ini biasanya dilakukan di sungai dengan maksud agar darah hewan yang disembelih menetes di atas air sungai yang mengalir sehingga segala sumpah yang pernah dibuat oleh para leluhur pada masa lalu dibawa pergi oleh air sungai. Darah hewan yang disembelih itu diartikan sebagai segala kesalahan dan perbuatan yang jahat yang merugikan dan menghalang kedua pasangan yang akan menikah.

Alat dan bahan yang dibutuhkan demi terlaksananya upacara tersebut adalah hewan kurban (Ayam, Babi, atau Kambing yang harus dimakan sampai selesai dan tidak dibawa pulang ), tempat sirih beserta sirih pinang, uang saku untuk pembicara yakni dari pihak laki - laki sebesar Rp100.000 dan pihak perempuan sebesar Rp50.000 dan juga uang logam, sopi yang dibawa oleh kedua mempelai masing - masing satu botol, lidi lontar yang terdiri dari dua jenis yakni ketmone (lidi simbol laki laki yakni yang lurus saja) dan ketfeto (lidi simbol perempuan yakni yang bercabang). Selain itu juga bahan - bahan lainnya yang harus dipersiapkan adalah baskom, keranjang, nasi dan lain sebagainya.

\section{b. Unsur - Unsur Matematika Yang Terkandung Dalam Acara Adat Thelas Keta}

Tabel 1. Unsur - Unsur Matematika Yang Terkandung Dalam Acara Adat Thelas Keta

\begin{tabular}{|c|c|c|}
\hline No & $\begin{array}{l}\text { Alat dan bahan yang digunakan dalam } \\
\text { acara adat thelas keta }\end{array}$ & $\begin{array}{l}\text { Konsep matematika yang terkandung dalam } \\
\text { acara adat thelas keta }\end{array}$ \\
\hline 1. & Keta (Lidi) & - Konsep garis \\
\hline 2. & Uang logam & - Konsep bangun datar lingkaran \\
\hline 3. & Kabi (Tempat sirih) & - Konsep bangun datar persegi panjang \\
\hline 4. & Keranjang & - Konsep bangun datar belah ketupat \\
\hline 5. & Selendang & - Konsep bangun datar belah ketupat \\
\hline 6. & Baskom & - Konsep bangun datar lingkaran \\
\hline
\end{tabular}

\section{c. Hubungan Antara Acara Adat Thelas Keta dengan Konsep - konsep Matematika}

Berdasarkan uraian pembahasan dan fakta lapangan ditemukan bahwa kaitan antara etnomatematika acara adat thelas keta dengan matematika dapat dilihat dari segi alat dan bahan yang digunakan dalam upacara tersebut yakni : 


\section{Keta (Lidi)}
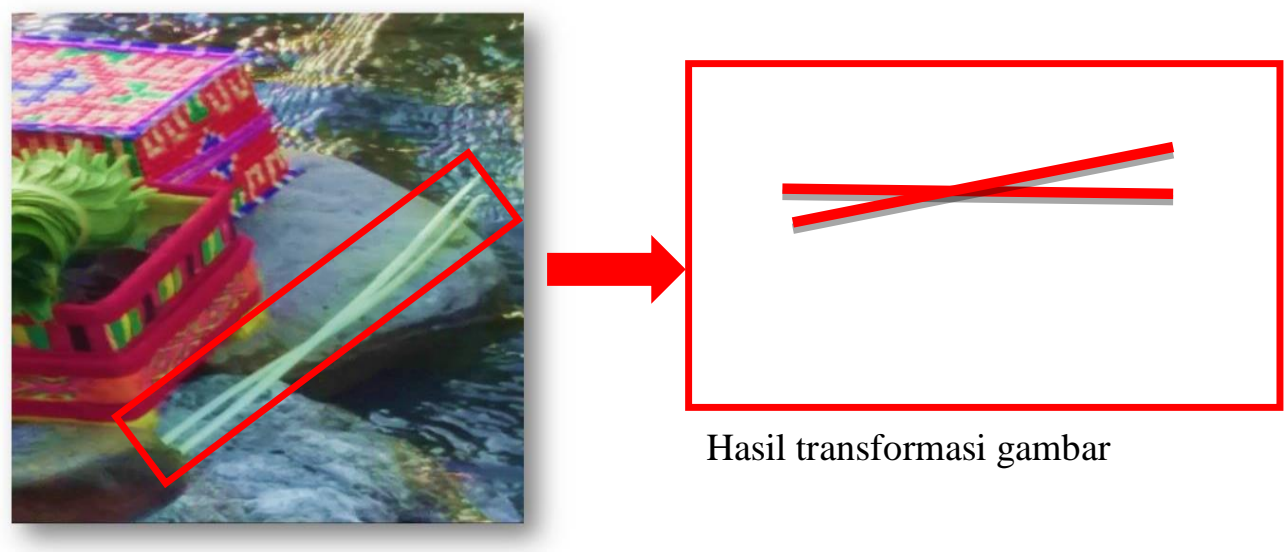

Hasil transformasi gambar

Gambar 1. Keta (Lidi)

Keta (lidi) adalah sebutan masyarakat dawan yang merujuk pada tulang daun lontar. Dalam kaitannya dengan upacara adat thelas keta, lidi yang dibawa oleh kedua mempelai tersebut memiliki makna sebagai pembatas atau penghalang sehingga lidi ini akan ditarik dan dibiarkan hanyut terbawa oleh air sungai. Hal ini dimaksudkan agar segala halangan yang telah terjadi akibat peperangan di masa lalu dibawa oleh air sungai ke laut. Konsep matematika yang terdapat pada lidi yang dibawa oleh kedua mempelai dalam acara adat thelas keta adalah konsep garis yang biasanya dipelajari oleh siswa SMP kelas VII semester genap. Konsep garis yang dimaksudkan adalah bentuk dari lidi tersebut memanjang seperti sebuah garis.

\section{Uang Logam}

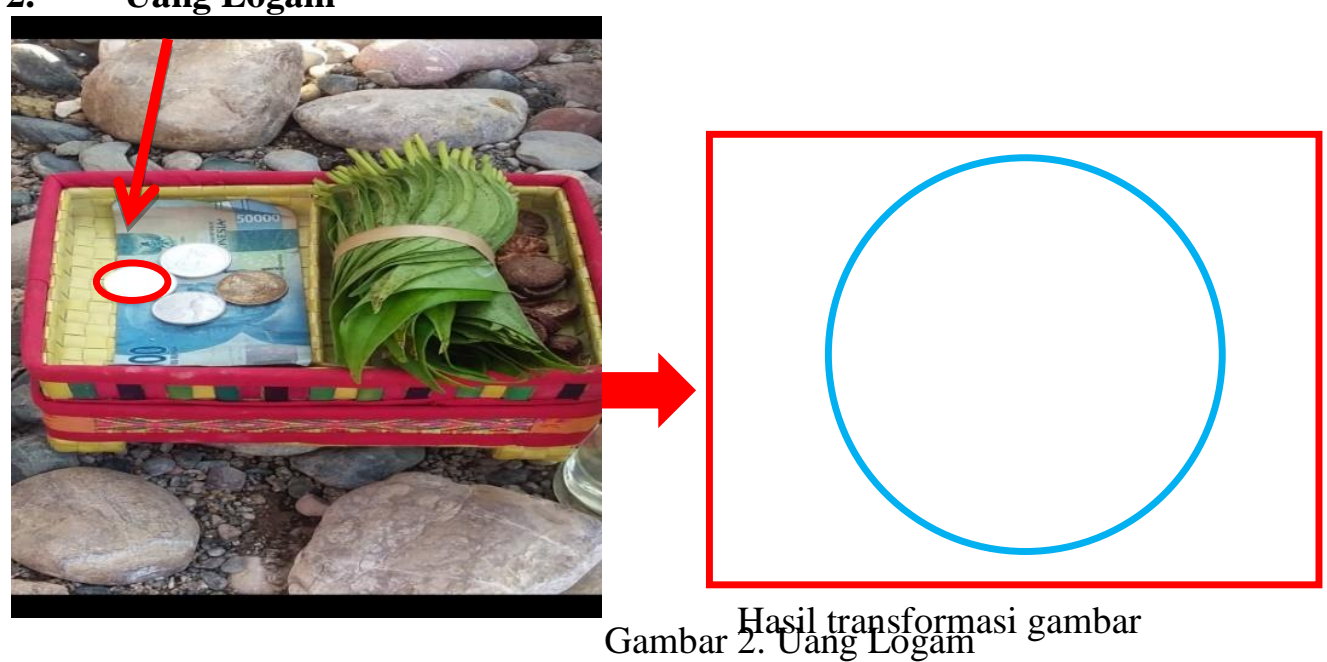

Uang logam yang dibawa dalam upacara adat thelas keta adalah simbol halangan yang ada dalam diri kita yang nantinya akan dibuang bersamaan dengan lidi sehingga segala halangan-halangan yang ada dalam diri kita dibiarkan hanyut terbawa oleh air sungai. Dari gambar 3, Konsep matematika yang termuat adalah bangun datar lingkaran. 


\section{3. $\quad K a b i($ Tempat Sirih)}
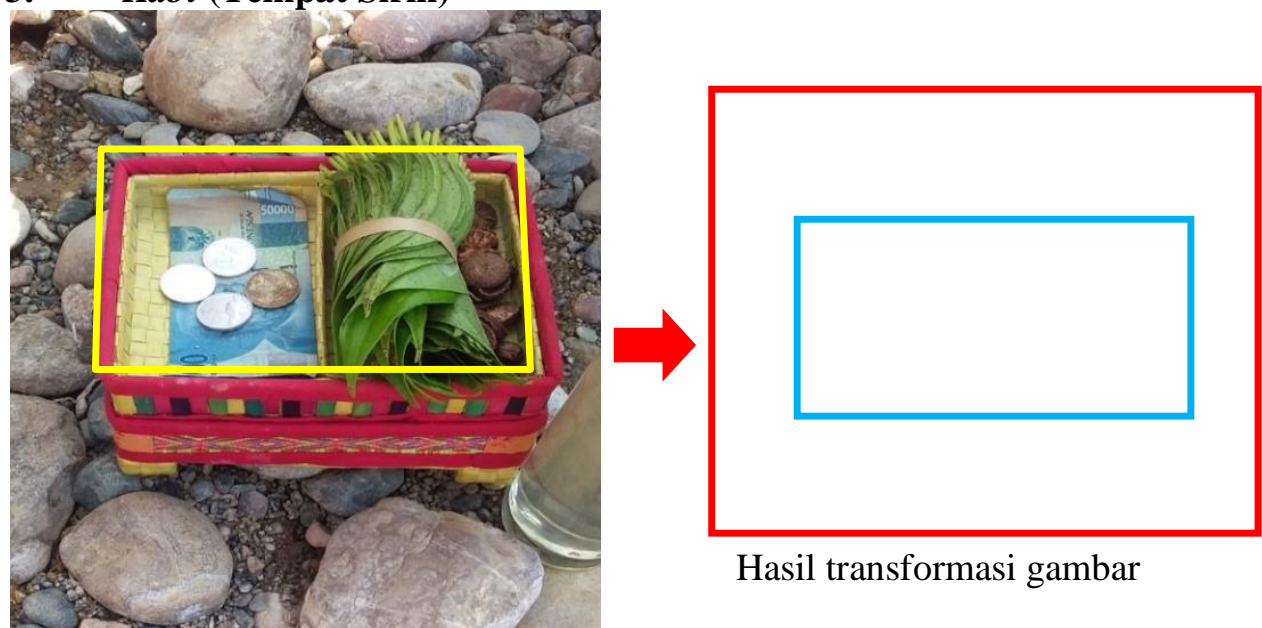

Hasil transformasi gambar

\section{Gambar 3. Kabi (Tempat Sirih)}

Kabi adalah tempat untuk menyimpan sirih pinang yang terbuat dari anyaman daun lontar. Selain sebagai tempat untuk menyimpan sirih pinang, dalam acara adat thelas keta tempat sirih dimanfaatkan untuk menyimpan beberapa uang logam yang akan digunakan pada saat upacara thelas keta dan juga uang saku untuk para penutur adat. Dari gambar 4, terlihat bahwa konsep matematika yang terkandung pada tempat sirih tersebut adalah konsep bangun datar persegi panjang.

\section{Keranjang}
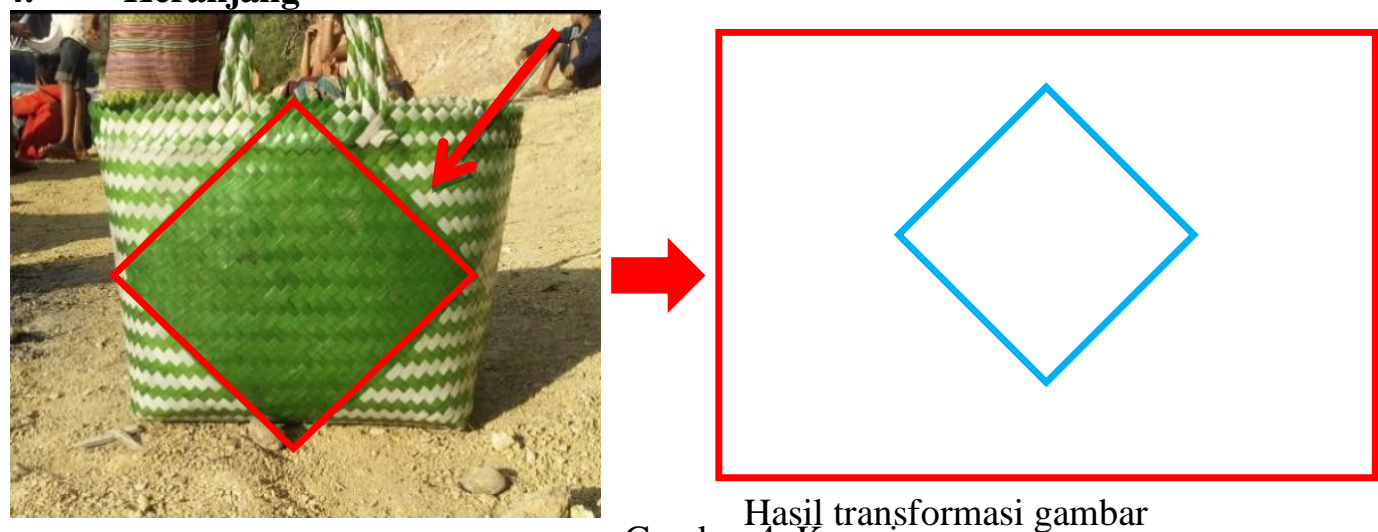

Hasil transformasi gambar

Gambar 4. Keranjang

Keranjang merupakan wadah yang dibuat dari serat yang dianyam. Kegunaan keranjang dalam upacara adat thelas keta adalah untuk menyimpan barang - barang yang diperlukan dalam acara thelas keta seperti piring, sendok, baskom, tempat sirih dan lain sebagainya. Anyaman pada keranjang seperti yang ditunjukan pada gambar 5 membentuk sebuah konsep matematika yakni bangun datar belah ketupat.

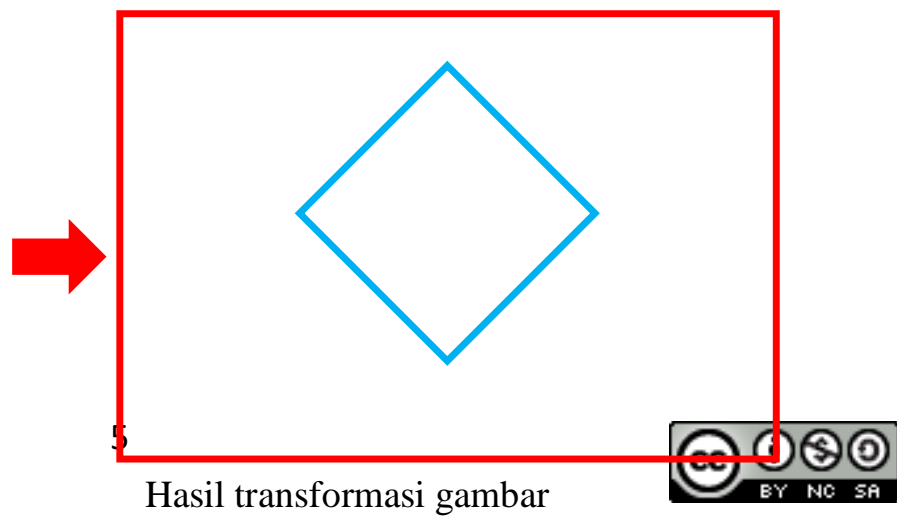



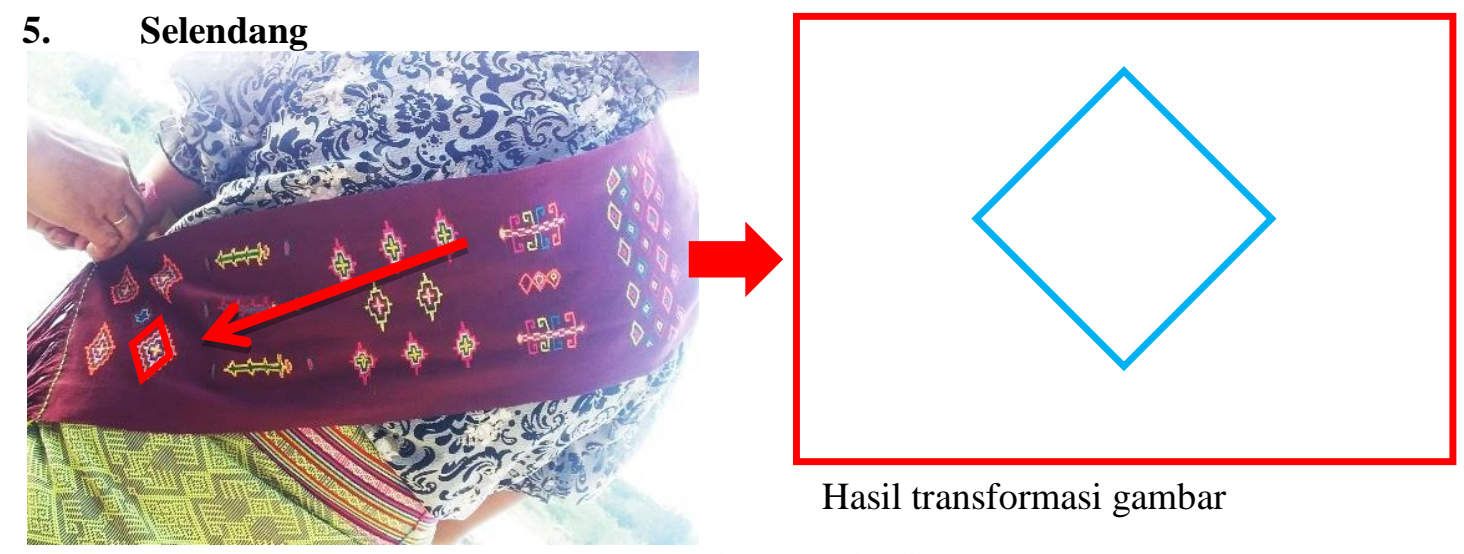

Gambar 5. Selendang

Selendang adalah pakaian tradisional bermotif yang wajib digunakan oleh kedua mempelai dalam acara adat thelas keta dengan panjang $1-2$ meter dan lebar berkisar antara $15-20 \mathrm{~cm}$. Motif yang terdapat pada selendang menunjukan kekhasan suatu daerah. Motif juga mengandung arti sebagai ekspresi jati diri serta mengandung makna kedekatan manusia dengan lingkungannya.

Motif yang terdapat pada selendang sangat beragam, tergantung pada suku yang melakukan upacara adat thelas keta. Namun dalam penelitian ini motif yang dikaji pada gambar 6 merupakan motif dari masyarakat Miomaffo Barat khususnya Desa Lemun. Konsep matematika yang termuat dalam gambar tersebut adalah konsep bangun datar belah ketupat. Motif kain tenun yang ada di Kabupetan TTU ada empat motif, yaitu Buna, Sotis, Futus dan Mapauf (Deda, et al., 2019). Motif kain tersebut selain menjembatani pemahaman siswa di sekolah dalam belajar matematika, juga sekaligus untuk memperkuat pendidikan karakter (Amsikan \& Deda, 2020).

\section{Baskom}

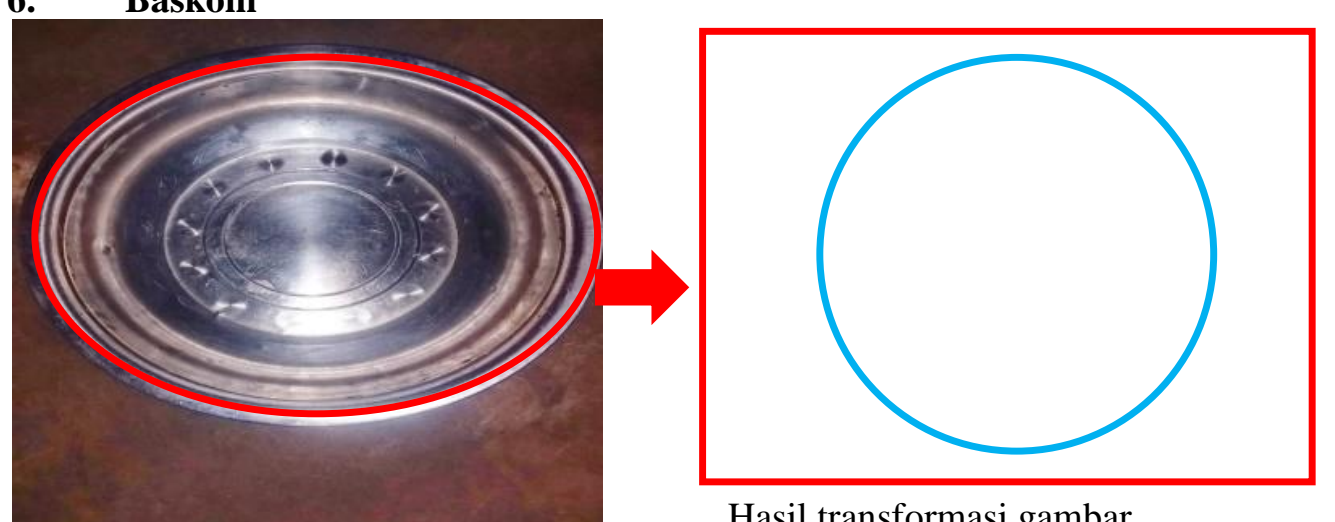

Hasil transformasi gambar

Gambar 6. Baskom

Hewan kurban yang biasanya dibawa saat upacara adat thelas keta adalah ayam, babi atau kambing. Hewan-hewan kurban tersebut akan disembelih di sungai dan membiarkan darahnya mengalir bersama aliran air dengan tujuan agar pertumpahan darah yang telah terjadi antara para leluhur pada zaman dulu tidak terulang kembali. Apabila dikaitkan dengan ilmu matematika, hewan-hewan kurban yang dibawa oleh kedua mempelai dalam acara thelas keta termasuk dalam konsep perbandingan.

\section{Kesimpulan}

Berdasarkan pembahasan di atas dapat disimpulkan bahwa matematika dan budaya merupakan dua hal yang mempunyai kaitan erat dalam kehidupan sehari - hari. Keterkaitan antara matematika dan budaya dikenal dengan istilah etnomatematika. Etnomatematika merupakan matematika yang terdapat dalam budaya. Salah satu contohnya adalah etnomatematika yang terdapat dalam acara adat thelas keta. Konsep - konsep matematika yang terdapat dalam acara adat thelas keta antara lain, 
konsep garis, konsep bangun datar lingkaran, konsep bangun datar belah ketupat dan konsep bangun datar lingkaran.

Dengan demikian peneliti merekomendasikan agar guru mengembangkan pembelajaran berbasis budaya dalam hal ini berbasis acara adat thelas keta pada materi konsep perbandingan, konsep garis, konsep bangun datar lingkaran, dan konsep bangun datar belah ketupat. Tujuannya adalah untuk menjembatani matematika dengan budaya lokal sebagai salah satu sumber pembelajaran yang konkret sehingga siswa terlibat aktif dalam kegiatan belajar mengajar.

\section{Daftar Pustaka}

Amsikan, S. \& Nahak, S. 2017. Hubungan Konsep Ruang Ume Kbubu Desa KaenBaun Kabupaten Timor Tengah Utara dendan Konsep Geometri. Prosiding Konferensi Nasional Penelitian Matematika dan pembelajarannya II (KNPM II) Universitas Muhamadiyah Surakarta, 18 Maret 2017, hal.168-175.

Amsikan, S. \& Deda, Y. N. 2020. Penguatan Pendidikan Karakter Dalam Pembelajaran Matematika Dengan Menggunakan Motif Kain Tenun Insana. JPPM (Jurnal Pengabdian dan Pemberdayaan Masyarakat), 4(1), 25-30

Angriani, A. D. 2013. Keefektifan Model Kooperatif Tipe Tai Dengan Pendekatan Realistik Dalam Pembelajaran Sistem Persamaan Linear Dua Variabel Di Kelas VIII SMP Negeri 4 Sinjai Utara. Jurnal Matematika Dan Pembelajaran (MAPAN), hal. 57.

Astri Wahyuni, Ayu Anji Wedaring Tias \& Budiman Sani. 2013. Peran Etnomatematika Dalam Membangun Bangsa. Seminar Nasional Matematika dan Pendidikan Matematika FMIPA UNY (hal. 2). Yogyakarta: Prosiding.

Deda, Y. N. \& Amsikan, S. 2019. Geometry Concept on the Motifs of Woven Fabric Kefamenanu Community. Jramathedu 4 (1), 23-30.

Deda Y. N. \& Disnawati, H. 2017. Hubungan Motif Kain Tenun Masyarakat Suku Dawan - Timor Dengan Matematika Sekolah. Prosiding Konferensi Nasional Penelitian Matematika dan pembelajarannya II (KNPM II) Universitas Muhamadiyah Surakarta, 18 Maret 2017, hal.201209.

Deda Y. N. \& Disnawati, H. 2019. Buku Ajar Etnomatematika Kawasan Perbatasan NKRI-Timor Leste. Deepublish: Yogyakarta.

Funan, F.X. \& Mamoh, O. 2019. Eksplorasi Etnomatematika Uem Le'u Insana dalam Kaitannya dengan Konsep Geometri. Range: Jurnal Pendidikan Matematika, 1(1),56-69.

Sirate, F. 2012. Implementasi Etnomatematika Dalam Pembelajaran Matematika Pada Jenjang Sekolah Dasar. Lentera Pendidikan, hal. 41.

Son, A.L. 2017. Study Ethnomatematics: Pengungkapan Konsep Matematika dan Karakter Siswa pada Permainan Kelereng Masyarakat Suku Dawan. Journal Of MEDIVES 1 (2), 100-110

Spradley, \& James, P. (2006). Metode Etnografi. Yogyakarta: Tiara Wacana.

Turmudi. 2017. Apa Mengapa dan Bagaimana Implementasi Dalam Pembelajaran Matematika Dalam Kelas. Seminar Nasional Matematika (2nd Senatik) Program Studi Pendidikan Matematika FPMIPATI - Universitas PGRI Semarang (hal. 3). Semarang: Prosiding. 